\title{
Obtaining molybdenyl glycolate using ethanol as a salting out solvent
}

\author{
(C) Alexey V. Klienkov, ${ }^{*+}$ and Alexander A. Petukhov \\ Department of Synthetic Rubber Technology. Kazan National Research Technological University. \\ Karl Marx St., 68. Kazan, 420015. Republic of Tatarstan. Russia. \\ Phone:+7 (843)231-42-16.E-mail: klienkov.aleksey@gmail.com; petukhov-aa@yandex.ru
}

\begin{abstract}
*Supervising author; ${ }^{+}$Corresponding author
Keywords: monoethylene glycol, ammonium paramolybdate, glycol solution, molybdenum, molybdenyl glycolate, epoxidation catalyst.
\end{abstract}

Abstract
The global production of propylene oxide is more than 8 million tons/year and is increasing by more than 5\% annually. Almost all domestic propylene oxide ( 72 thousand tons/year) is produced at PJSC Nizhnekamskneftekhim (Russia) according to one of the variants of the Halcon process epoxidation of propylene with ethylbenzene hydroperoxide (HPEB) in the presence of a molybdenum catalyst.

One of the most important tasks arising in improving the process for the joint production of styrene and propylene oxide at PJSC Nizhnekamskneftekhim (Russia) is the search and development of new catalysts and catalytic systems, one of the stages of this process - the epoxidation of propylene with HPEB.

The complex molybdenum catalyst used in the production of propylene oxide, having high activity and selectivity, has several disadvantages, namely: low dissolved molybdenum content, high consumption of ethylbenzene hydroperoxide for its production, and instability during storage.

Thus, the problem of obtaining a catalyst with a higher content of dissolved molybdenum and increasing the stability of the catalytic complex, i.e. development of new catalytic systems with the best technological and technical and economic indicators.

An analysis of the scientific and technical literature and patent publications showed that in the synthesis of a complex molybdenum catalyst, various molybdenum compounds of both organic and inorganic nature can be used.

During the study, molybdenum-containing solutions based on ammonium paramolybdate and monoethylene glycol were tested, distillation distillation products prepared by distilling off excess monoethylene glycol by strengthening under vacuum. Molybdenyl glycolate was isolated by salting out with ethanol from a distillation bottoms product.

\section{References}

[1] R. Landau, D. Brown, J.L. Russell, D. Collard. Epoxidation of olefins. In Sat "New petrochemical processes and prospects for the development of petrochemicals." Based on materials from the VII World Petroleum Congress in Mexico. Ed. I.V. Crippled. Moscow: Chemistry. 1970. P.75-85. (russian)

[2] N.N. Lebedev. Chemistry and technology of basic organic and petrochemical synthesis. Moscow: Chemistry. 1975. 776p. (russian)

[3] B.R. Serebryakov and others. The current state of production and consumption of propylene oxide. Thematic. overview. Ser. "Petrochemicals and oil shale processing". Moscow: TsNIITEneftekhim. 1971. 93p. (russian)

[4] V.A. Belyaev, A.A. Petukhov, Z.A. Pokrovskaya, I.A. Mayzlakh, I.V. Vinogradova, A.N. Bushin. Synthesis of isoprene based on the liquid phase oxidation of C5 hy drocarbons. Thematic. overview. Ser. "Prom. SK ". Moscow: Ts NIITEneftekhim. 1975. P.13-20. (russian)

[5] L.A. Petukhova. Synthesis of a molybdenum-containing catalyst for hydroperoxide epoxidation of olefins. Thesis Ph.D. Kazan, KNITU. 2011. P.131. (russian) 
[6] R.Z. Shaikhutdinov. Energy-saving technology for the preparation of starting reagents for the synthesis of a molybdenum-containing olefin epoxidation catalyst. Thesis Ph.D. Kazan, KNITU. 2011. P.147. (russian)

[7] A.A. Petukhov, B.R. Serebryakov, A.G. Liakumovich, N.I. Matrosov, D.S. Salyamov,

K.K. Khaziev, S.A. Kuravina. A method of preparing a molybdenum-containing catalyst for the epoxidation of propylene. Patent of Russia No. 1358142 Published: 04/20/1997 BI: 9711

[8] A.A. Petukhov, G.Z. Sakhapov. A method of preparing a soluble epoxidation catalyst. Patent of Russia No. 2114694. Published: November 20, 2005. BI: 32/2005

[9] A.A. Petukhov, B.R. Serebryakov, I.M. Vasiliev, V.A. Belokurov, R.M. Galimzyanov, A.I. Myshkin. A method of obtaining a soluble molybdenum-containing epoxidation catalyst. Patent of Russia No. 2119384. Published: July 20, 2006. BI: 20/2006

[10] V.A. Belokurov, V.M. Busygin, I.M. Vasiliev, R.M. Galimzyanov, V.P. Zuev, A.F. Minullin, A.I. Myshkin, A.A. Petukhov, R.M. Akhmetov. Olefin epoxidation catalyst and method for its preparation. Patent of Russia No. 2240181. Published: November 20, 2004. Bull. Number 32. 